\title{
Second-hand smoke generated by combustion and electronic smoking devices used in real scenarios: Ultrafine particle pollution and age-related dose assessment
}

\author{
Carmela Protano $^{\mathrm{a}}$, Maurizio Manigrasso ${ }^{\mathrm{b}}$, Pasquale Avino ${ }^{\mathrm{b}, \mathrm{c}}$, Matteo Vitali ${ }^{\mathrm{a}, *}$ \\ a Department of Public Health and Infectious Diseases, Sapienza University of Rome, P.le Aldo Moro, 5, 00185 Rome, Italy \\ b Department of Technological Innovations, INAIL, Via IV Novembre 144, 00187 Rome, Italy \\ c Department of Agricultural, Environmental and Food Sciences (DiAAA), University of Molise, via F. De Sanctis, 86100 Campobasso, Italy
}

\section{A R T I C L E I N F O}

\section{Keywords:}

Ultrafine particles

Secondhand smoke

Age-related dose

Traditional smoking products

Electronic smoking devices

IQOS $^{\oplus}$

\begin{abstract}
A B S T R A C T
Aerosol measurements were carried out in a model room where both combustion (conventional and hand-rolled cigarettes, a cigar and tobacco pipe) and non-combustion (e-cigarette and IQOS ${ }^{\circledR}$ ) devices were smoked. The data were used to estimate the dose of particles deposited in the respiratory systems of individuals from 3 months to 21 years of age using the multiple-path particle dosimetry (MPPD) model. Regardless of the smoking device, the highest doses were received by infants, which reached $9.88 \times 10^{8}$ particles $/ \mathrm{kg}$ bw during a cigar smoking session. Moreover, $60 \%$ to $80 \%$ of the particles deposited in the head region of a 3-month-old infant were smaller than $100 \mathrm{~nm}$ and could be translocated to the brain via the olfactory bulb. The doses due to second-hand smoke from electronic devices were significantly lower, below $1.60 \times 10^{8}$ particles $/ \mathrm{kg}$ bw, than those due to combustion devices. Dosimetry estimates were $50 \%$ to $110 \%$ higher for IQOS ${ }^{\circledR}$ than for e-cigarettes.
\end{abstract}

\section{Introduction}

Particle matter (PM) pollution remains one of the most critical environmental risks to public health. Indeed, over the years, scientific evidence has shown an increasing number of adverse effects in humans linked to exposure to $\mathrm{PM}$ ( $\mathrm{PM}_{10}$ and its subfractions), such as cardiovascular and pulmonary diseases (WHO, 2013), neurodegenerative diseases (Heusinkveld et al., 2016), and negative birth outcomes after intrauterine exposure (Lamichhane et al., 2015). In addition, the International Agency for Research on Cancer (IARC) recently classified $\mathrm{PM}$ in outdoor air pollution as a group 1 carcinogen to humans (IARC, 2015). Based on the growing evidence of human risks related to PM exposure, the World Health Organization (WHO) designated 50 and $25 \mu \mathrm{g} / \mathrm{m}^{3}$ as reference values for outdoor $\mathrm{PM}_{10}$ and $\mathrm{PM}_{2.5}$ concentrations (mean daily levels for general population exposure), respectively (WHO, 2006). However, even if these standards are met, the population is not completely protected against risks related to PM exposure because these guidelines consider only $2 \mathrm{PM}$ fractions $\left(\mathrm{PM}_{10}\right.$ and $\left.\mathrm{PM}_{2.5}\right)$ and only outdoor PM exposure levels were provided (neglecting indoor environments). Several studies have shown that exposure to fine particles $\left(\mathrm{PM}_{2.5}\right)$ can generate many adverse effects on human health related to particle pollution (Dreher et al., 1996; Tsai et al., 2000; WHO,
2013; Feng et al., 2016). Moreover, the toxicity per unit mass of the particles has been demonstrated to increase as their sizes decrease. Consequently, scientific interest has focused on the particle surface area and number of particles rather than on the particle mass, underlining the relevance of submicronic particles (SMPs, $<1 \mu \mathrm{m}$ ) and ultrafine particles (UFPs, 0.01-0.1 $\mu \mathrm{m}$ ) (Manigrasso et al., 2013; Oberdörster et al., 2005a, 2005b). Particles can be released from several heterogeneous sources, which are quite different for outdoor and indoor environments (Isaxon et al., 2015; Manigrasso et al., 2017). While the main source of outdoor PM in urban areas is vehicular traffic (Avino et al., 2016; Manigrasso and Avino, 2012), cooking activities and smoking are the most common sources of indoor PM levels, together with the ambient particles that infiltrate from the outdoors and the particles formed indoors from precursors emitted both indoors and outdoors (Morawska and Salthammer, 2015). In particular, indoor PM concentrations dramatically increase during smoking (Protano et al., 2014). To fully understand how smoking impacts the concentrations of indoor particles, comparisons between PM emissions from smoking and other combustion sources are necessary. De Marco et al. (2016), for example, reported PM levels from cigarette smoke that were 2-3 times higher than those released by heavy duty trucks. Furthermore, Protano et al. (2016) reported that spending $1 \mathrm{~h}$ in an indoor environment in

\footnotetext{
* Corresponding author at: Department of Public Health and Infectious Diseases, Sapienza University of Rome, Piazzale Aldo Moro, 5, 00185 Rome, Italy.

E-mail address: matteo.vitali@uniroma1.it (M. Vitali).
} 
which a single traditional cigarette had been smoked is equivalent to spending half an hour in a heavy traffic area in terms of SMPs exposure. To minimize exposure to air pollutants (including fine and ultrafine particles) generated by tobacco smoke, many countries have introduced smoking bans in public places. However, the smoke-free policy cannot be applied to household environments, where tobacco smoke remains an important source of pollution (Protano et al., 2012a, 2012b).

The aerosol size of the particles emitted by smoking is also an important issue. Becquemin et al. (2010) showed that a high percentage of particles emitted from cigarette smoke are UFPs. However, most studies published on this topic are limited to conventional cigarettes and do not include other ways of smoking, such as the use of cigars, pipes, and electronic and heat-not-burn devices. Notably, some previous studies have shown that the use of electronic cigarettes (e-cigs) indoors is not exempt from the emission of fine and ultrafine particles, though e-cigs result in much lower emissions of fine and ultrafine particles than conventional cigarettes (Pellegrino et al., 2012; Ruprecht et al., 2014). Furthermore, the results of a recent study showed that e-cig aerosols are a potential high-dose source of particles that can reach the deepest part of the respiratory system (Manigrasso et al., 2014). To our knowledge, these experiments, which were performed to assess the particle emission from all manners of smoking, were conducted using smoking machines. This kind of simulation allows the measurement of only the smoke produced by burning tobacco (the so-called sidestream smoke) and neglects the smoke exhaled by the smoker during active smoking (exhaled mainstream smoke). Exhaled mainstream and sidestream smoke are two different routes of gaseous and particulate pollutant generation that together characterize the phenomenon of "passive smoking" (also called environmental tobacco smoke, ETS) (Moldoveanu and St.Charles, 2007). Thus, contributions from both exhaled mainstream and sidestream smoke must be considered when evaluating pollutant emission during smoking. To further complicate this scenario, ETS has been recently demonstrated to result from the combination of two phenomena: second-hand smoke (SHS) and thirdhand smoke (THS). SHS is the environmental smoke near people who are smoking or just finished smoking, and THS is the environmental smoke that persist for a long period (up to weeks) and can be adsorbed and released by skin and hair, furnishings, clothing, etc. long after cigarettes, cigars or pipes are smoked. Therefore, it is essential that studies performed to evaluate exposure to ETS and its specific contaminants can assess the independent contributions of SHS and THS (Protano and Vitali, 2011).

The general aims of this study were 1 ) to evaluate the emissions of SMPs with diameters ranging from 5.0 to $560 \mathrm{~nm}$ arising from the "real" use (by already-smoker volunteers) of smoke products, including combustion (conventional and hand-rolled cigarettes, pipes, and cigars) and non-combustion products (e-cigs and IQOS ${ }^{\circledR}$, a new electronic device that heats a cigarette-like stick without combustion), and 2) to estimate the exposure of individuals passively exposed to SHSs derived from the use of the above-mentioned smoke products, tracing specific exposure profiles for population groups according to age (infants, children, adolescents, and adults).

\section{Materials and methods}

\subsection{Smoking devices and experimental plan}

In the present study, two types of smoking devices were evaluated:

1) combustion devices: i) a conventional cigarette (Pall Mall ${ }^{\circledR}$ San Francisco; the nicotine, tar and carbon monoxide content was 0.7, 8.0, and $9.0 \mathrm{mg}$, respectively), ii) a hand-rolled cigarette (Golden Virginia $^{\circledR}$ tobacco hand-rolled with a Rizla ${ }^{\circledR}$ Blue Regular Rolling Paper), iii) a cigar (Italian Toscanello ${ }^{\circledR}$ cigar), and iv) a pipe charged with tobacco (Amphora ${ }^{\circledR}$ Original Blend)

2) heat-not-burn electronic devices: i) $\operatorname{IQOS}^{\circledR}$, a recently commercialized device that heats a cigarette-like stick without combustion used with a Marlboro $^{\circledR}$ Balance stick, and ii) an e-cig (Smooke ${ }^{\circledR}$ ESMART (L) e-cig) filled with Smooke ${ }^{\circledR}$ Light e-liquid containing nicotine at $9 \mathrm{mg} \mathrm{mL}^{-1}$.

Six sets of experiments (one for each smoking device) were carried out in triplicate; each experiment was based on one or more smoking sessions, which were performed by volunteers who were currently smokers in a $52.7 \mathrm{~m}^{3}$ test room with a door and window that were both closed.

Three smoking sessions at 1-h time intervals $\left(\Delta \mathrm{t}_{1}, \Delta \mathrm{t}_{2}, \Delta \mathrm{t}_{3}\right)$ for each smoking device (conventional cigarette, hand-rolled cigarette, e-cig and IQOS $^{\circledast}$ ) were performed. During each session, a single cigarette or IQOS $^{\circledR}$ stick was smoked. For the e-cig, 12 puffs per session were taken because traditional smoking typically consists of 10-12 puffs per cigarette (Perkins et al., 2012). Since cigars and tobacco pipes are typically smoked differently than cigarettes, they were smoked in a single smoking session until the cigar or pipe tobacco was finished, which resulted in longer time intervals than for the other devices (approximately 30 and $45 \mathrm{~min}$, respectively).

For each type of smoking device, aerosol measurement started 5 min before the first smoking session and lasted $200 \mathrm{~min}$ in order to follow the aerosol concentration decay. Before changing the smoking device, the door and window were opened to allow the atmosphere of the room to rebalance. It is well-known that the rebalance depends on several factors (ventilation, outdoor wind speed, temperature difference, indoor humidity, etc.); thus, door and window were opened overnight. Next experiment started two hours later to achieve stable conditions of test room temperature and relative humidity. Throughout the experiment, temperature and relative humidity were measured (mean values \pm SD were equal to $22.2 \pm 0.6{ }^{\circ} \mathrm{C}$ and $41.0 \pm 5.6 \%$, respectively).

\subsection{Smoking volunteers}

The volunteer smokers were four employees of the Sapienza University of Rome (three male and one female of 60, 58, 53 and 37 years of age that were already smokers). The study was non-sponsored and was approved by the local ethical committee (Policlinico Umberto I/Sapienza University of Rome; protocol code 3520).

\subsection{Aerosol emission characterization}

Aerosol number-size distributions were measured by using a TSI Fast Mobility Particle Sizer (model 3091, FMPS, Shoreview, MN, USA). The instrument counts and classifies particles according to their electrical mobility in 32 size channels in the range of 5.6 to $560 \mathrm{~nm}$ with a temporal resolution of $1 \mathrm{~s}$. FMPS operates at high flow rate $\left(10 \mathrm{~L} \mathrm{~min}^{-1}\right)$ to minimize diffusion losses and at ambient pressure to prevent the evaporation of volatile and semivolatile particles (Manigrasso et al., 2013; TSI, 2015).

The air exchange rate $(\lambda)$ was calculated by using the tracer gas technique (Laussmann and Helm, 2011), where $\mathrm{CO}_{2}$ was used as the tracer gas. The $\mathrm{CO}_{2}$ was released from a cylinder into ambient air until a relatively stable concentration was reached; then, the decaying $\mathrm{CO}_{2}$ concentration was measured over time $(t)$. The temporal evolution of the $\mathrm{CO}_{2}$ concentration is described by Eq. (1), where $\lambda$ is the air exchange rate and $C_{i n}(t), C_{o}$ and $C_{\text {out }}$ are the indoor and outdoor $\mathrm{CO}_{2}$ concentrations (at $t=t$ and $t=0$ ), respectively:

$\ln \left(C_{\text {in }}(t)-C_{\text {out }}\right)=\ln \left(C_{0}-C_{\text {out }}\right)-\lambda t$

$\lambda$ is equal to $0.67 \mathrm{~h}^{-1}$, as calculated via linear regression analysis.

\subsection{Age-specific dose evaluation}

Dosimetry estimates were carried out using the multiple-path particle dosimetry (MPPD v2.1, ARA 2009, ARA, Arlington, VA, USA) 
model. The MPPD model was developed by the Hamner Institutes for Health Sciences and the Dutch National Institute for Public Health and the Environment (RIVM) (Asgharian et al., 2001) and is able to estimate the dose received by a person as a function of size and tracheobronchial and alveolar airway generation number. This model calculates the deposition and clearance of mono- and polydisperse aerosols in the respiratory systems of humans and rats (Anjilvel and Asgharian, 1995; Price et al., 2002). To estimate aerosol deposition doses as a function of age, dosimetry estimates were made using the age-specific symmetric model. This model assumes a dichotomous, branching, symmetric tree single path structure of the respiratory system. Ages of 3 and 23 months and 3, 8, 14 and 21 years were considered. The functional residual capacity (FRC), head volume, tidal volume and breathing frequency were determined by using the MPPD model. Nasal breathing was considered. To calculate the overall dose in the particle diameter range measured through FMPS, the MPPD model was run separately for the 32 FMPS size channels, where each was considered to be composed of a monodisperse aerosol. Spherical particles of unit density were assumed. Doses as functions of time $(D(t))$ were calculated as the number of particles deposited per kg body weight (bw); 5.7, 11.1, 13.5, 31.7, 55.9 and $65 \mathrm{~kg}$ bw were assumed for 3 months, 23 months, 3 years, 8 years, 14 years, and 21 years of age, respectively (USEPA, 2011).

The following equations were used:

i. dose size distributions as functions of time $(t)$ in the head $(\mathrm{H}$, nose and mouth), (Price et al., 2002) tracheobronchial (TB) and alveolar (A) regions (R):

$D_{i}^{R}(t)=F_{i}^{R} \times C_{i}(t) \times \frac{V_{t}}{b w},(R=H, T B, A)$

where $F_{i}^{R}$ is the deposition fraction at a given $R$ region of particles classified in the $i$ th FMPS size channel (calculated by the MPPD model), $C_{i}(\mathrm{t})$ is the concentration of particles in the ith FMPS size channel as a function of time, and $V_{t}$ is the tidal volume.

Cumulative dose size distributions were calculated at the maximum aerosol concentration and are reported in the discussion for the $\mathrm{H}$ region as the percent of the total particle dose deposited $\left(C D_{i}^{H}\left(t_{\text {Max }}\right) \%\right)$.

ii. total regional doses:

$D^{R}(t)=\sum_{i=1}^{32} D_{i}^{R}(t),(R=H, T B, A)$

where 32 is the number of size classes;

iii. total dose in the respiratory system:

$D_{T o t}(t)=\sum_{R} D^{R}(t),(R=H, T B, A)$

In the discussion of the results, cumulative doses for $D_{T o t}(t)$ and $D^{R}(t)\left(C D_{T o t}\right.$ and $C D^{R}$, respectively) are reported for three consecutive 1$\mathrm{h}$ time intervals. Regional cumulative doses $\left(C D^{R}\right)$ are reported as a percentage of $C D_{T o t}$.

\subsection{Statistical elaboration}

Statistical analyses were carried out using IBM SPSS software (version 22.0 for Windows, Version 22.0. Armonk, NY: IBM Corp.). First of all, the normality of particles number concentrations distribution of each studied smoking devices was assessed using the one-sample Kolmogorov-Smirnov test. All set of data exhibited a normal distribution after natural log-transformation. Thus, one-way analysis of variance (ANOVA) with Bonferroni post-hoc tests was used to test differences in the means of particles number concentrations of all smoking devices.
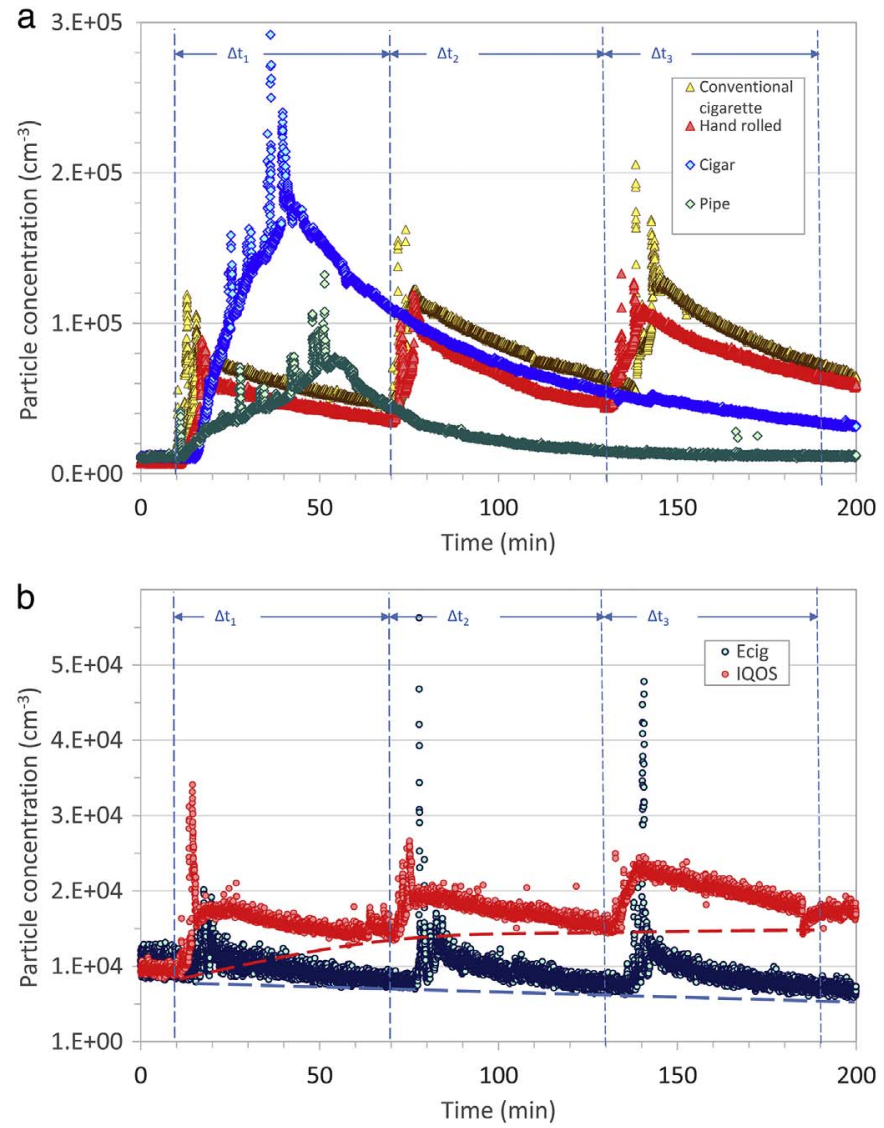

Fig. 1. Temporal trends for the total particle number concentrations in the test room (air exchange rate $=0.67 \mathrm{~h}^{-1}$ ) for (1a) aerosol emitted from combustion smoking devices (conventional cigarette, hand-rolled cigarette, tobacco pipe and cigar) and (1b) heat-notburn devices (e-cigarette and IQOS ${ }^{\circledast}$ ).

\section{Results and discussion}

\subsection{SMP emission from the studied smoking devices}

Fig. 1a and $\mathrm{b}$ shows the temporal trends in the total particle number concentration for combustion (conventional cigarette, hand-rolled cigarette, tobacco pipe and cigar) and heat-not-burn (IQOS ${ }^{\circledR}$ and e-cig) smoking devices, respectively. Peak concentrations ranging from $1.2 \times 10^{5}$ to $2.9 \times 10^{5}$ particles $\mathrm{cm}^{-3}$ were reached when combustion occurred, whereas peak concentrations for heat-not-burn devices were below $4.7 \times 10^{4}$ particles $\mathrm{cm}^{-3}$.

The temporal trends for conventional and hand-rolled cigarettes were substantially similar; for both kinds of cigarettes, a 1-h time interval after each smoking section was not enough to allow the particle concentration to decrease to the background level. Lower concentrations were measured for the hand-rolled cigarette than for the conventional cigarette, probably due to the looser packing of tobacco in the hand-rolled cigarette (on average $609 \mathrm{mg}$ tobacco in the hand-rolled cigarette compared with $793 \mathrm{mg}$ tobacco in the conventional cigarette), resulting in a lower amount of burnt tobacco per unit time.

Particle emissions from the e-cig were lower than from IQOS ${ }^{\circledR}$, although the transient peak values were higher. Therefore, for the e-cig, a 1-h time interval from device activation was sufficient to allow particle decay to reach baseline values, but not for IQOS ${ }^{\circledR}$. At the end of each smoking session, the particle number concentration followed an increasing trend for IQOS ${ }^{\circledR}$ and a decreasing trend for the e-cig (dotted lines in Fig. 1b), likely due to the particle removal mechanisms of deposition, particle coagulation and phase change.

For both cigar and tobacco pipe, a single but longer smoking section was considered (approximately 30 and $45 \mathrm{~min}$, respectively, compared 
a
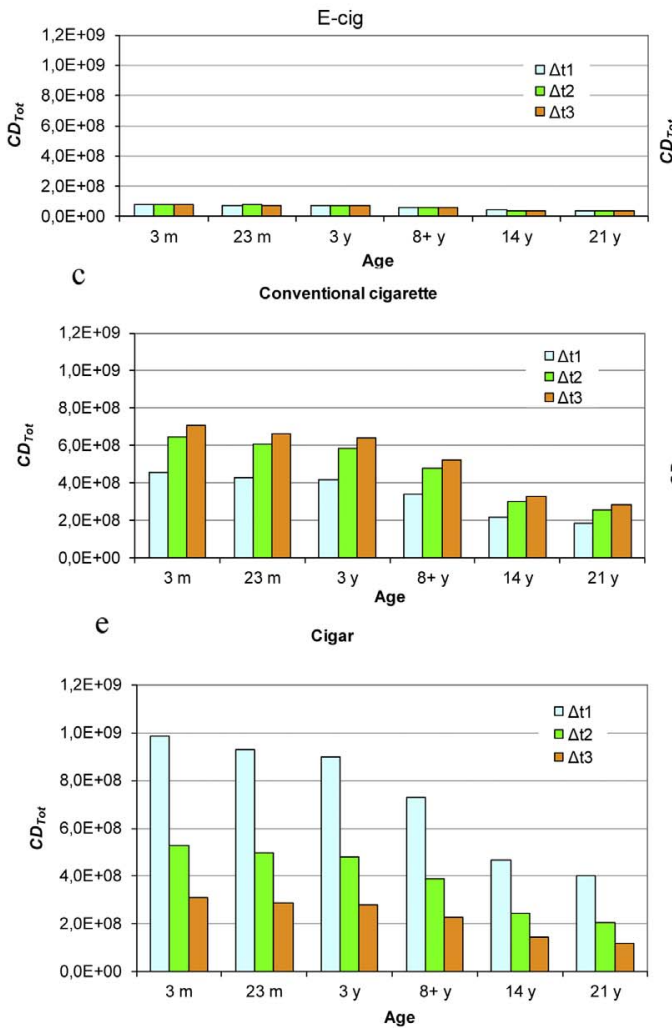
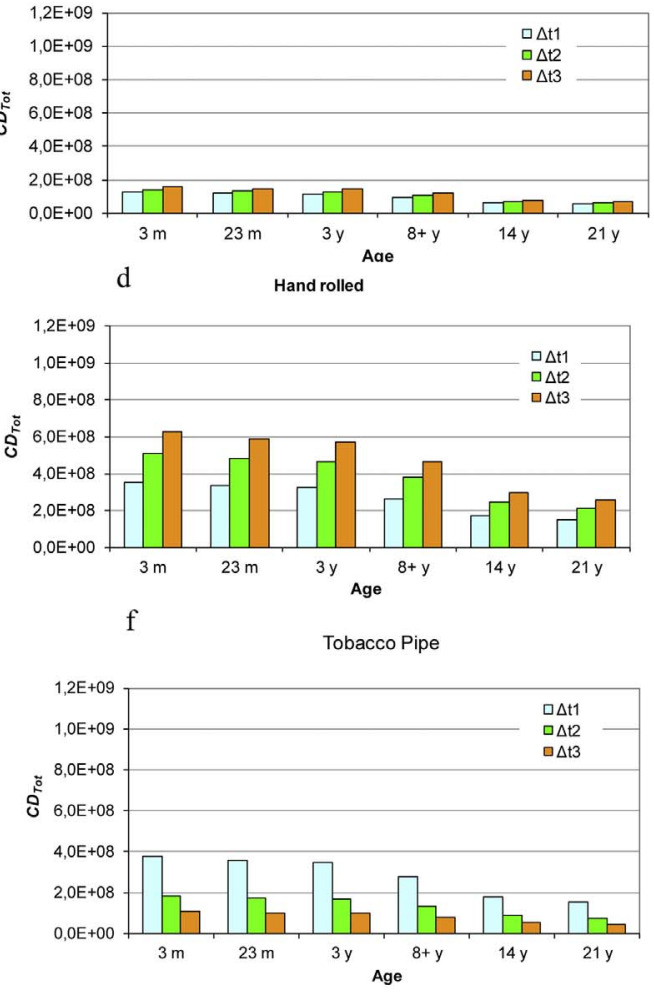

Fig. 2. Cumulative doses $C D_{T o t}$ (particles $/ \mathrm{kg}$ bw) of aerosol deposited in the respiratory system of 3 and 23 month old and 3, 8, 14 and 21 year old individuals for (2a) an e-cigarette, (2b) IQOS ${ }^{\circledast},(2 \mathrm{c})$ a conventional cigarette, (2d) a hand-rolled cigarette $\left(\Delta \mathrm{t}_{1}, \Delta \mathrm{t}_{2}, \Delta \mathrm{t}_{3}\right.$ represent three 1-h intervals during which a single smoking session was carried out), (2e) a cigar and (2f) a tobacco pipe (a single smoking session was considered). with $4 \mathrm{~min}$ for each combustion and non-combustion cigarette). The particle emission rates for cigars estimated by Klepeis et al. (2003) ranged from 0.2 to $0.7 \mathrm{mg} \mathrm{min}^{-1}$, which were lower than those for cigarettes $\left(0.7\right.$ to $\left.0.9 \mathrm{mg} \mathrm{min}^{-1}\right)$. Therefore, the higher concentration levels measured for the cigar (up to $2.9 \times 10^{5}$ particles $\mathrm{cm}^{-3}$ ) were due to its longer smoking session. In contrast, although the smoking session for the pipe was longer than that for the cigar, their peak concentrations were almost the same as that for the cigarette. This was due to the emission rate of the pipe, which is lower than that for cigarettes and cigars, as can be inferred from the lower slope of the increasing part of the relevant concentration curves (Fig. 1a). ANOVA test and Bonferroni post hoc revealed a significant difference in the means of particles number concentrations emitted by each smoking devices ( $p$ values < 0.05).

\subsection{Dosimetry estimates and exposure to SHS}

For all smoking devices considered, cumulative doses, $C D_{T o t}$ (particles/kg bw), which indicate the "theoretical" uptake of subjects passively exposed to SHS, increased with decreased age (Fig. 2). These initial results confirm and quantify (based on experimental data) the great concern of the scientific community related to ETS exposure of the paediatric population: the same smoking session, regardless of the device used, exhibited much greater risk for a passively exposed child than for an adult. This is even more concerning because children are especially vulnerable to the adverse effects due to environmental toxicants (Grigg, 2004) and passive smoking. In particular, ETS exposure during childhood has been associated to acute health adverse effects, including respiratory infections (Cao et al., 2015), asthma and other respiratory disorders (Jayes et al., 2016), and long term diseases on several apparatus, such as cardiovascular and pulmonary systems (Jounala et al., 2013; Stocks and Sonnappa, 2013).

Higher doses were estimated for the combustion devices than for the e-cig or IQOS ${ }^{\circledR}$. Among them, the highest dose $\left(9.88 \times 10^{8}\right.$ particles $/ \mathrm{kg}$ bw) was theoretically deposited in the respiratory system of the
3 month old infant during the cigar smoking session. The lowest dose $\left(3.55 \times 10^{8}\right.$ particles $/ \mathrm{kg}$ bw) was estimated after the first smoking session of the hand-rolled cigarette. Significantly lower doses (lower than $1.60 \times 10^{8}$ particles $/ \mathrm{kg}$ bw) were due to SHS from the e-cig and IQOS $^{\circledast}$. For all three smoking sessions, dosimetry estimates were $50 \%$ to $110 \%$ higher for IQOS $^{\circledR}$ than for the e-cig. Such behaviour may be due to aerosol emission from the e-cig occurring only when it is puffed. In contrast, sidestream emission from IQOS ${ }^{\circledR}$ also occurs when it is activated, even if it is not puffed (O'Connell et al., 2015). With the exception of the e-cig, aerosol doses increased from one smoking session to the next because the 1-h time interval from the beginning of the smoking session was not sufficient to allow for the complete decay of the aerosol concentration.

Table 1 shows the regional cumulative doses $\left(C D^{R}\right)$ as a percentage of $C D_{T o t}$ and as a function of the age of the exposed individual.

Even though both the cigar and pipe were smoked in a single session, we considered three 1-h time intervals $\left(\Delta \mathrm{t}_{1}, \Delta \mathrm{t}_{2}, \Delta \mathrm{t}_{3}\right)$, as for the other smoking devices, to estimate the dose received by an individual residing in the same room after the cigar/pipe was extinguished.

For all considered smoking devices, the greatest percentage of particles was deposited in the alveolar region, where they could induce alveolar inflammation and, once accessing blood circulation, may reach other organs (Oberdörster et al., 2005a, 2005b). The lower percentage estimated for infants and children is probably due to the higher filtrating efficiency of their head region compared with adults. For instance, considering conventional cigarette SHS, $20 \%$ and $62 \% C D_{T o t}$ were deposited in the head and alveolar region, respectively, of a 3month-old infant. In a 21-year-old subject, the percentages were $13 \%$ and $68 \%$. In fact, the deposition efficiency in the head region is a function of the particle Stokes number, which varies inversely with the cubic power of the airway diameter (Xu and Yu, 1986). Thus, due to the smaller dimension of the high respiratory way, more particles are retained in the head region of infants.

Fig. 3 shows the cumulative dose size distributions in the head $(\mathrm{H})$ region at the maximum aerosol concentration for 3-month-old infants, 
Table 1

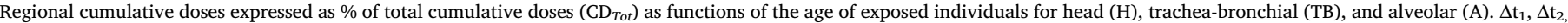
$\Delta \mathrm{t}_{3}$ represent three 1-h intervals during which a single smoking session was carried out (for cigar and tobacco pipe a single smoking session was considered).

\begin{tabular}{|c|c|c|c|c|c|c|c|c|c|c|c|c|c|c|c|c|c|c|c|}
\hline \multirow[t]{2}{*}{ Age } & \multirow[t]{2}{*}{ Intervals } & \multicolumn{3}{|l|}{ e-cig } & \multicolumn{3}{|c|}{ IQOS $^{\circledast}$} & \multicolumn{3}{|c|}{ Conv. cig. } & \multicolumn{3}{|c|}{ Hand-rolled } & \multicolumn{3}{|l|}{ Cigar } & \multicolumn{3}{|l|}{ Pipe } \\
\hline & & $\mathrm{H} \%$ & TB $\%$ & A \% & $\mathrm{H} \%$ & TB $\%$ & A \% & $\mathrm{H} \%$ & TB \% & A \% & $\mathrm{H} \%$ & TB \% & A $\%$ & $\mathrm{H} \%$ & TB $\%$ & A \% & $\mathrm{H} \%$ & TB $\%$ & A $\%$ \\
\hline \multirow[t]{3}{*}{3 months } & $\Delta \mathrm{t}_{1}$ & 20 & 21 & 59 & 19 & 20 & 61 & 20 & 19 & 61 & 19 & 20 & 61 & 20 & 19 & 61 & 20 & 19 & 61 \\
\hline & $\Delta \mathrm{t}_{2}$ & 23 & 24 & 53 & 19 & 20 & 61 & 20 & 18 & 62 & 19 & 19 & 62 & 21 & 18 & 61 & 20 & 19 & 61 \\
\hline & $\Delta t_{3}$ & 22 & 24 & 54 & 18 & 20 & 62 & 20 & 18 & 62 & 19 & 19 & 62 & 23 & 18 & 59 & 22 & 22 & 56 \\
\hline \multirow[t]{3}{*}{23 months } & $\Delta \mathrm{t}_{1}$ & 23 & 21 & 56 & 22 & 20 & 58 & 24 & 19 & 57 & 23 & 20 & 57 & 24 & 19 & 57 & 24 & 19 & 57 \\
\hline & $\Delta \mathrm{t}_{2}$ & 26 & 24 & 50 & 22 & 20 & 58 & 24 & 18 & 58 & 23 & 19 & 58 & 26 & 18 & 56 & 24 & 19 & 57 \\
\hline & $\Delta t_{3}$ & 25 & 24 & 51 & 21 & 20 & 59 & 25 & 18 & 57 & 23 & 19 & 58 & 28 & 18 & 54 & 25 & 22 & 53 \\
\hline \multirow[t]{3}{*}{3 years } & $\Delta \mathrm{t}_{1}$ & 23 & 20 & 57 & 22 & 19 & 59 & 24 & 18 & 58 & 23 & 19 & 58 & 25 & 18 & 57 & 25 & 18 & 55 \\
\hline & $\Delta \mathrm{t}_{2}$ & 25 & 23 & 52 & 22 & 19 & 59 & 24 & 17 & 59 & 23 & 18 & 59 & 26 & 17 & 57 & 24 & 18 & 58 \\
\hline & $\Delta t_{3}$ & 24 & 23 & 53 & 21 & 19 & 60 & 25 & 17 & 58 & 24 & 18 & 58 & 28 & 17 & 55 & 25 & 22 & 53 \\
\hline \multirow[t]{3}{*}{8 years } & $\Delta \mathrm{t}_{1}$ & 18 & 16 & 66 & 17 & 15 & 68 & 19 & 14 & 67 & 18 & 14 & 68 & 20 & 14 & 66 & 20 & 14 & 66 \\
\hline & $\Delta \mathrm{t}_{2}$ & 20 & 20 & 18 & 17 & 15 & 68 & 19 & 14 & 67 & 18 & 14 & 68 & 21 & 14 & 65 & 19 & 14 & 67 \\
\hline & $\Delta \mathrm{t}_{3}$ & 18 & 18 & 64 & 16 & 14 & 70 & 20 & 14 & 66 & 19 & 14 & 67 & 23 & 14 & 63 & 19 & 17 & 64 \\
\hline \multirow[t]{3}{*}{14 years } & $\Delta \mathrm{t}_{1}$ & 16 & 19 & 65 & 16 & 18 & 66 & 17 & 18 & 65 & 16 & 18 & 66 & 17 & 18 & 65 & 17 & 18 & 65 \\
\hline & $\Delta \mathrm{t}_{2}$ & 19 & 21 & 60 & 15 & 19 & 66 & 17 & 17 & 66 & 16 & 18 & 66 & 19 & 17 & 64 & 17 & 18 & 65 \\
\hline & $\Delta \mathrm{t}_{3}$ & 18 & 21 & 60 & 14 & 18 & 68 & 18 & 17 & 65 & 17 & 17 & 66 & 20 & 18 & 62 & 18 & 20 & 62 \\
\hline \multirow[t]{3}{*}{21 years } & $\Delta \mathrm{t}_{1}$ & 13 & 21 & 66 & 12 & 20 & 68 & 13 & 20 & 67 & 12 & 20 & 68 & 13 & 20 & 67 & 13 & 20 & 67 \\
\hline & $\Delta \mathrm{t}_{2}$ & 17 & 23 & 60 & 13 & 20 & 67 & 12 & 19 & 69 & 12 & 20 & 68 & 13 & 20 & 67 & 12 & 20 & 68 \\
\hline & $\Delta \mathrm{t}_{3}$ & 15 & 23 & 62 & 12 & 19 & 69 & 12 & 20 & 68 & 12 & 20 & 68 & 14 & 20 & 66 & 15 & 22 & 63 \\
\hline
\end{tabular}

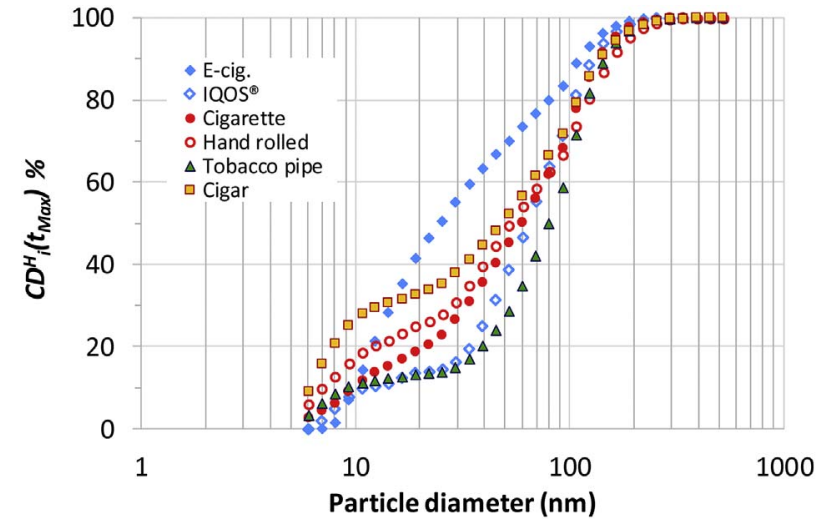

Fig. 3. Cumulative dose size distributions in the head $(\mathrm{H})$ region at the maximum aerosol concentration for 3-month-old infants, reported as a percent of the total particle dose deposited $\left(C D_{i}^{H}\left(t_{\operatorname{Max}}\right) \%\right)$.

reported as a percent of the total particle dose deposited $\left(C D_{i}^{H}\left(t_{\text {Max }}\right) \%\right)$. Approximately $60 \%$ to $80 \%$ of the deposited particles had sizes smaller than $100 \mathrm{~nm}$. The health relevance of these particles is empathized by the study of Maher et al. (2016), which speculated that such particles can reach the brain through the olfactory bulb. The results of this study demonstrate the abundant presence of combustion-derived magnetite and of other metal-bearing nanoparticles (sizes below $200 \mathrm{~nm}$ ) with median shortest and longest diameters of approximately 14 and $18 \mathrm{~nm}$, respectively.

The present study has some limitations. First of all, it is well-known that there is an individual variability on the amount of inhaled and exhaled smoke that could affect particles concentrations levels. However, to account for such variability, the three replicate tests for each smoking device were carried out by different volunteers. Further, the results refer to a single air exchange rate; these results, although representative of those occurring in domestic environments, do not account for the possible air exchange rate variability that would affect particle concentrations levels.

In conclusion, some relevant results emerged from this research. First, even if it is well-known that traditional combustion smoking devices, such as cigarettes, pipes and cigars, are among the most prevalent sources of air pollutants in indoor environments, recent scientific studies have evidenced that improved methods for quantifying particle emission from indoor sources and consequent exposure/risk assessments are still needed (Morawska et al., 2012). The data presented here can help bridge this gap. In addition, we demonstrated that both of the tested non-combustion smoking devices emitted SMPs during their use, supporting the ban of "electronic" smoking devices indoors, which is still not applied in all countries. Smoking should also be avoided in private places because of the slow decay of SMPs, especially for combustion smoking devices; thus, even if an individual smokes alone in an enclosed environment, the environment remains polluted and contributes to the exposure of others residing with the smoker. This is of particular concern for infants and children, which in addition to being more susceptible than adults to adverse effects, made up the age group in our study that took in the largest quantities of SMPs per $\mathrm{kg}$ bw, of which a great number of very small particles can easily reach the alveolar region.

\section{Funding}

This research did not receive any specific grant from funding agencies in the public, commercial, or not-for-profit sectors.

\section{References}

Anjilvel, S., Asgharian, B., 1995. A multiple-path model of particle deposition in the rat lung. Fundam. Appl. Toxicol. 28, 41-50. http://dx.doi.org/10.1006/faat.1995.1144. Asgharian, B., Hofmann, W., Bergmann, R., 2001. Particle deposition in a multiple-path model of the human lung. Aerosol Sci. Technol. 34, 332-339. http://dx.doi.org/10. 1080/02786820119122.

Avino, P., Protano, C., Vitali, M., Manigrasso, M., 2016. Benchmark study on fine-mode aerosol in a big urban area and relevant doses deposited in the human respiratory tract. Environ. Pollut. 216, 530-537. http://dx.doi.org/10.1016/j.envpol.2016.06. 005 .

Becquemin, M.H., Bertholon, J.F., Bentayeb, M., et al., 2010. Third-hand smoking: indoor measurements of concentration and sizes of cigarette smoke particles after resuspension. Tob. Control. 19, 347-348. http://dx.doi.org/10.1136/tc.2009.034694.

Cao, S., Yang, C., Gan, Y., Lu, Z., 2015. The Health Effects of Passive Smoking: An Overview of Systematic Reviews Based on Observational Epidemiological Evidence. PLoS One 10, e0139907. http://dx.doi.org/10.1371/journal.pone.0139907.

De Marco, C., Ruprecht, A.A., Pozzi, P., et al., 2016. Particulate matters from diesel heavy duty trucks exhaust versus cigarettes emissions: a new educational antismoking instrument. Multidiscip. Respir. Med. 11, 2. http://dx.doi.org/10.1186/s40248-0160042-7.

Dreher, K., Jaskot, R., Richards, J., Lehemann, J., 1996. Acute pulmonary toxicity of site fractionated ambient air particulate matter. Am. J. Respir. Crit. Care Med. 153, A15.

Feng, S., Gao, D., Liao, F., Zhou, F., Wang, X., 2016. The health effects of ambient $\mathrm{PM}_{2.5}$ and potential mechanisms. Ecotoxicol. Environ. Saf. 128, 67-74. http://dx.doi.org/ 10.1016/j.ecoenv.2016.01.030.

Grigg, J., 2004. Environmental toxins; their impact on children's health. Arch. Dis. Child. 89, 244-250. http://dx.doi.org/10.1136/adc.2002.022202.

Heusinkveld, H.J., Wahle, T., Campbell, A., et al., 2016. Neurodegenerative and 
neurological disorders by small inhaled particles. Neurotoxicology 19, 94-106. http://dx.doi.org/10.1016/j.neuro.2016.07.007.

International Agency for Research on Cancer (IARC), 2015. Monographs on the Evaluation of Carcinogenic Risks to Humans. In: Outdoor Air Pollution. Vol. 109 WHO Press, Lyon, France.

Isaxon, C., Gudmundsson, A., Nordina, E.Z., et al., 2015. Contribution of indoor-generated particles to residential exposure. Atmos. Environ. 106, 458-466. http://dx.doi. org/10.1016/j.atmosenv.2014.07.053.

Jayes, L., Haslam, P.L., Gratziou, C.G., Powell, P., Britton, J., Vardavasm, C., JimenezRuizm, C., Leonardi-Beem, J., Tobacco Control Committee of the European Respiratory Society, 2016. SmokeHaz: systematic reviews and meta-analyses of the effects of smoking on respiratory health. Chest 150, 164-179. http://dx.doi.org/10. 1016/j.chest.2016.03.060.

Jounala, M., Magnussen, C.G., Raitakari, O.T., 2013. Parental smoking produces longterm damage to vascular function in their children. Curr. Opin. Cardiol. 28, 569-574. http://dx.doi.org/10.1097/HCO.0b013e3283642882.

Klepeis, N.E., Apte, M.G., Gundel, L.A., Sextro, R.G., Nazaroff, W.W., 2003. Determining size-specific emission factors for environmental tobacco smoke particles. Aerosol Sci. Technol. 37, 780-790. http://dx.doi.org/10.1080/02786820300914.

Lamichhane, D.K., Leem, J.H., Lee, J.Y., Kim, H.C., 2015. A meta-analysis of exposure to particulate matter and adverse birth outcomes. Environ. Health Toxicol. 3, e2015011. http://dx.doi.org/10.5620/eht.e2015011.

Laussmann, D., Helm, D., 2011. Air change measurements using tracer gases: methods and results. Significance of air change for indoor air quality. In: Mazzeo, M. (Ed.), Chemistry, Emission Control, Radioactive Pollution and Indoor Air Quality. InTech, Rijeka, Croatia, pp. 365-406.

Maher, B.A., Ahmed, I.A.M., Karloukovski, V., et al., 2016. Magnetite pollution nanoparticles in the human brain. Proc. Natl. Acad. Sci. U. S. A. 113, 10797-10801. http://dx.doi.org/10.1073/pnas.1605941113.

Manigrasso, M., Avino, P., 2012. Fast evolution of urban ultrafine particles: implications for deposition doses in the human respiratory system. Atmos. Environ. 51, 116-123. http://dx.doi.org/10.1016/j.atmosenv.2012.01.039.

Manigrasso, M., Stabile, L., Avino, P., Buonanno, G., 2013. Influence of measurement frequency on the evaluation of short-term dose of sub-micrometric particles during indoor and outdoor generation events. Atmos. Environ. 67, 130-142. http://dx.doi org/10.1016/j.atmosenv.2012.10.059.

Manigrasso, M., Buonanno, G., Fuoco, F.C., Stabile, L., Avino, P., 2014. Aerosol deposition doses in the human respiratory tree of electronic cigarette smokers. Environ. Pollut. 196C, 257-267. http://dx.doi.org/10.1016/j.envpol.2014.10.013.

Manigrasso, M., Vitali, M., Protano, C., Avino, P., 2017. Temporal evolution of ultrafine particles and of alveolar deposited surface area from main indoor combustion and non-combustion sources in a model room. Sci. Total Environ. 598, 1015-1026. http://dx.doi.org/10.1016/j.scitotenv.2017.02.048.

Moldoveanu, S.C., St.Charles, F.K., 2007. Differences in the chemical composition of the particulate phase of inhaled and exhaled cigarette mainstream smoke. Beiträge zur Tabakforschung International/Contrib. Tob. Res. 2, 290-302. http://dx.doi.org/10. 2478/cttr-2013-0834.

Morawska, L., Salthammer, T., 2015. Indoor air: contemporary sources, exposures and global implications. Atmos. Environ. 106, 375. http://dx.doi.org/10.1016/j. atmosenv.2015.02.044.

Morawska, L., Afshari, A., Bae, G.N., et al., 2012. Indoor aerosols: from personal exposure to risk assessment. Indoor Air 23, 462-487. http://dx.doi.org/10.1111/ina.12044.

Oberdörster, G., Maynard, A., Donaldson, K., et al., 2005a. Principles for characterizing the potential human health effects from exposure to nanomaterials: elements of a screening strategy. Part. Fibre Toxicol. 2, 8-43. http://dx.doi.org/10.1186/17438977-2-8.
Oberdörster, G., Oberdörster, E., Oberdörster, J., 2005b. Nanotoxicology: an emerging discipline evolving from studies of ultrafine particles. Environ. Health Perspect. 113, 823-839. http://dx.doi.org/10.1289/ehp.7339.

O'Connell, G., Wilkinson, P., Burseg, K.M.M., Stotesbury, S.J., Pritchard, J.D., 2015. Heated tobacco products create side-stream emissions: implications for regulation. Int. J. Environ. Anal. Chem. 2, 5. http://dx.doi.org/10.4172/2380-2391.1000163.

Pellegrino, R.M., Tinghino, B., Mangiaracina, G., et al., 2012. Electronic cigarettes: an evaluation of exposure to chemicals and fine particulate matter (PM). Ann. Ig. 24, 279-288.

Perkins, K.A., Karelitz, J.L., Giedgowd, G.E., Conclin, C.A., 2012. The reliability of puff topography and subjective responses during ad lib smoking of a single cigarette. Nicotine Tob. Res. 14, 490-494. http://dx.doi.org/10.1093/ntr/ntr150.

Price, O.T., Asgharian, B., Miller, F.J., Cassee, F.R., de Winter-Sorkina, R., 2002. Multiple Path Particle Dosimetry Model (MPPD v. 1.0): a Model for Human and Rat Airway Particle Dosimetry, v 1.0. National Institute for public health and the environment (RIVM), Bilthoven, The Netherlands.

Protano, C., Vitali, M., 2011. The new danger of thirdhand smoke: why passive smoking does not stop at secondhand smoke. Environ. Health Perspect. 119, a422. http://dx. doi.org/10.1289/ehp.1103956.

Protano, C., Andreoli, R., Manini, P., Guidotti, M., Vitali, M., 2012a. A tobacco-related carcinogen: assessing the impact of smoking behaviours of cohabitants on benzene exposure in children. Tob. Control. 21, 325-329. http://dx.doi.org/10.1136/tc.2010. 039255.

Protano, C., Andreoli, R., Manini, P., Vitali, M., 2012b. How home-smoking habits affect children: a cross-sectional study using urinary cotinine measurement in Italy. Int. J. Public Health. 57, 885-892. http://dx.doi.org/10.1007/s00038-012-0354-0.

Protano, C., Cattaruzza, M.S., Osborn, J.F., Vitali, M., 2014. Indoor particulate matter and secondhand smoke: simulation of an exposure scenario. Ann. Ig. 26, 186-189. http:// dx.doi.org/10.7416/ai.2014.1975.

Protano, C., Manigrasso, M., Avino, P., Sernia, S., Vitali, M., 2016. Second-hand smoke exposure generated by new electronic devices (IQOS ${ }^{\circledR}$ and e-cigs) and traditional cigarettes: submicron particle behaviour in human respiratory system. Ann. Ig. 28, 109-112. http://dx.doi.org/10.7416/ai.2016.2089.

Ruprecht, A.A., De Marco, C., Pozzi, P., et al., 2014. Comparison between particulate matter and ultrafine particle emission by electronic and normal cigarettes in real-life conditions. Tumori 100, e24-e27. http://dx.doi.org/10.1700/1430.15833.

Stocks, J., Sonnappa, S., 2013. Early life influences on the development of chronic obstructive pulmonary disease. Ther. Adv. Respir. Dis. 7, 161-173. http://dx.doi.org/ $10.1177 / 1753465813479428$.

Tsai, F.C., Smith, K.R., Vichit-Vadakan, N., Ostro, B.D., Chestnut, L.G., Kungskulniti, N., 2000. Indoor/outdoor $\mathrm{PM}_{10}$ and $\mathrm{PM}_{2.5}$ in Bangkok, Thailand. J. Expo. Anal. Environ. Epidemiol. 10, 15-26. http://dx.doi.org/10.1038/sj.jea.7500071.

TSI Particle Technology, 2015. Available online: http://www.tsi.com/Fast-MobilityParticle-Sizer-Spectrometer-3091/\# (last accessed on 24 Nov 2016).

United States Environmental Protection Agency (USEPA), 2011. Exposure factors handbook. In: 2011 Edition (Final). EPA/600/R-09/052F, 2011. U.S. Environmental Protection Agency, Washington, DC.

World Health Organization (WHO), 2006. WHO Air quality guidelines for Particulate Matter, Ozone, Nitrogen Dioxide, and Sulfur Dioxide. Global Update, 2005. Summary of Risk Assessment, 2005. WHO Press, Geneva, Switzerland.

World Health Organization (WHO), 2013. Health Effects of Particulate Matter. Policy Implications for Countries in Eastern Europe, Caucasus and Central Asia. Regional Office for Europe of WHO, Copenhagen, Denmark.

Xu, G.B., Yu, C.P., 1986. Effects of age on deposition of inhaled aerosols in the human lung. Aerosol Sci. Technol. 5, 349-357. http://dx.doi.org/10.1080/ 02786828608959099. 